\title{
Article \\ Can Industrial Restructuring Improve Urban Air Quality?-A Quasi-Experiment in Beijing during the COVID-19 Pandemic
}

\author{
Chenlu Tao ${ }^{1}\left(\mathbb{D}\right.$, Zhilin Liao $^{1}$, Mingxing $\mathrm{Hu}^{1}{ }^{1}$, Baodong Cheng ${ }^{1, *}$ and Gang Diao ${ }^{2, *}$ \\ 1 School of Economics and Management, Beijing Forestry University, Beijing 100083, China: \\ taochenlu@bjfu.edu.cn (C.T.); lz17210589@bjfu.edu.cn (Z.L.); mingxinghu@outlook.com (M.H.) \\ 2 Business College, Lishui University, Lishui 323020, China \\ * Correspondence: baodong@bjfu.edu.cn (B.C.); diaogang2021@outlook.com (G.D.)
}

Citation: Tao, C.; Liao, Z.; Hu, M.; Cheng, B.; Diao, G. Can Industrial Restructuring Improve Urban Air Quality?-A Quasi-Experiment in Beijing during the COVID-19

Pandemic. Atmosphere 2022, 13, 119 https://doi.org/10.3390/ atmos13010119

Academic Editor: Célia Alves

Received: 30 November 2021

Accepted: 9 January 2022

Published: 12 January 2022

Publisher's Note: MDPI stays neutral with regard to jurisdictional claims in published maps and institutional affiliations.

Copyright: (C) 2022 by the authors. Licensee MDPI, Basel, Switzerland. This article is an open access article distributed under the terms and conditions of the Creative Commons Attribution (CC BY) license (https:// creativecommons.org/licenses/by/ $4.0 /)$.

\begin{abstract}
The conflict between economic growth and environmental pollution has become a considerable bottleneck to future development throughout the world. The industrial structure may become the possible key factor in resolving the contradiction. Using the daily data of air quality from January to April in 2019 and 2020, we used the DID model to identify the effects of industrial structure on air quality by taking the COVID-19 pandemic as a quasi-experiment. The results show that, first, the impact of profit of the secondary industry on air quality is ten times higher than that of the tertiary industry. Therefore, the secondary industry is the main factor causing air pollution. Second, the effect of the reduction in the secondary industry on the improvement of air quality is better than that of the tertiary industry in Beijing. Therefore, the implementation of Beijing's non-capital function relief policy is timely and reasonable, and the adjustment of the industrial structure is effective in the improvement of air quality. Third, $\mathrm{PM}_{2.5}, \mathrm{NO}_{2}$, and $\mathrm{CO}$ are affected by the secondary and tertiary industries, where $\mathrm{PM}_{2.5}$ is affected most seriously by the second industry. Therefore, the transformation from the secondary industry to the tertiary industry can not only solve the problem of unemployment but also relieve the haze. Fourth, the result of $\mathrm{O}_{3}$ is in opposition to other pollutants. The probable reason is that the decrease of $\mathrm{PM}_{2.5}$ would lead to an increase in the $\mathrm{O}_{3}$ concentration. Therefore, it is difficult to reduce $\mathrm{O}_{3}$ concentrationby production limitation and it is urgent to formulate scientific methods to deal with $\mathrm{O}_{3}$ pollution. Fifth, the air quality in the surrounding areas can also influence Beijing. As Hebei is a key area to undertake Beijing's industry, the deterioration of its air quality would also bring pressure to Beijing's atmospheric environment. Therefore, in the process of industrial adjustment, the selection of appropriate regions for undertaking industries is very essential, which is worth our further discussion.
\end{abstract}

Keywords: industrial restructuring; air pollution; COVID-19; Beijing

\section{Introduction}

The conflict between economic growth and environmental pollution has become a considerable bottleneck to future development throughout the world [1]. Economic growth is the ultimate aim for every policymaker [2]. With the development of technology, production efficiency has been greatly improved, but due to the rapid expansion of production scale, economic development still brings many environmental problems [3]. During the deepening of urbanization, industrial agglomeration and the increase of urban population have caused many environmental pollution problems, especially the increasingly serious atmospheric environment problems. In contemporary society, air pollution has become a global city disease. In recent years, a large number of exhaust emissions have posed a challenge to the sustainable development of the economies of all countries around the world [4,5], and continue to endanger the health of urban residents. Air pollution causes urban residents to suffer from the respiratory system, heat, and skin disease [6-8]. Air pollution has become a stumbling block restricting regional economic development. Finding a 
possible development path that takes urban economic growth and air control into account has important theoretical and practical significance.

Academic circles have triggered a profound discussion on the trade-off between economic development and air pollution. Some scholars have found that the relationship between air quality and economic growth in Tunisia, a North African country, is suitable to be described by monotonic growth $[9,10]$. However, there is an inverted U-shaped relationship between economic growth and $\mathrm{CO}_{2}$ emissions in China [10], and there also exists a U-shape between economic growth and $\mathrm{SO}_{2}$ for the technical inefficiency [11]. Therefore, the relationship between air pollution and economic development cannot be described in a single dominant form [12]. The impact of economic development on air quality actually has complex structural characteristics, which brings great difficulties in solving the conflict between economic development and air quality. Further research shows that the industrial structure determines the distribution of production resources between different industries and has a decisive impact on resource consumption and pollutant emissions in the process of economic development $[13,14]$. Therefore, as an important link between human economic activities and air quality, the industrial structure may become the key factor in resolving the contradiction between economic development and the environment [15]. However, the research conclusions on the relationship between industrial structure and air quality are not totally consistent. Some scholars believe that the increase of heavy industry would aggravate $\mathrm{CO}_{2}$ emissions [16], leading to the deterioration of air quality [17], but some found that during the transformation of industrial structure from primary industry to secondary and tertiary industry, pollution showed a trend of rising first and then declining [18]. Instead, some scholars believe that there is a U-shaped relationship between industrial structure upgrading and haze, which is not in line with the environmental Kuznets hypothesis [19]. The above research provides a rich experience for the macro-understanding of the direct relationship between industrial structure and environmental pollution, but the research results are inconsistent due to many interference factors. Moreover, there are few studies that can clearly show the impact of industrial structure adjustment on AQI and specific pollutants, such as ozone, etc.

With the development of informationization and urbanization in China, city dis-eases are more and more apparent [20]. Beijing is the political center, cultural center, international exchange center, and scientific and technological innovation center of China. It has obvious big city diseases such as air pollution [21,22], which is highly representative. Air pollution in Beijing has gradually become a severe environmental issue, due to the continuing growth in energy consumption and the resulting multiple pollutant emissions [23]. To alleviate the city disease, Beijing has proposed the traffic restriction policy, and then the non-capital functions relieving strategy in Beijing in 2015, as a policy of relieving non-capital functions from Beijing was adopted by President $X_{i}$ in 2015. The non-capital functions refer to urban functions excluding administration, culture, international communication, and technical innovation [24]. The focus of the policy is to ease the general manufacturing industry and will bring about changes in the industrial structure. Therefore, Beijing has strong representativeness and can be used as a sample to study the impact of industrial structure adjustment on urban air quality [25]. Beijing's decentralization may bring hope to the solution of air quality problems. Studies have found that the traffic restriction policy can significantly improve the air quality, and AQI has decreased by $19 \%$ due to traffic restrictions based on even- and odd-numbered license plates [26]. However, Cao et al. estimated the traffic restriction policy in Beijing and found that although the traditional OLS regression showed that the traffic restriction policy had a strong effect, it had little impact on air quality when the breakpoint regression was used to solve the endogeneity [27]. Later, Li et al. also expressed support, believing that the non-capital functions relieving strategy in Beijing has little contribution to improving the atmospheric environment [28]. Studying the relationship between regional industrial structure adjustment and air quality helps to clarify the possible path of air pollution control. Assessing the impact of industrial restructuring brought about by the non-capital functions relieving strategy in Beijing on air quality is 
conducive to more comprehensive consideration of the formulation of national strategies. However, since many factors affect air pollution, the air quality improvement brought by industrial structure adjustment may be endogenous, and the effect of policies is difficult to evaluate. The COVID-19 pandemic provides an opportunity to analyze the effects on air quality of industrial structure adjustment as it has reduced human activities [29] and changed the industrial structure in a short time. The coronavirus disease had massive impacts on society and the economy across large parts of China, including Beijing [30-33]. Therefore, COVID-19-related restrictions, both mandated and voluntary, have, in effect, created a "natural experiment".

This study aims to clarify the impact of industrial restructuring on urban air quality, estimate the effect of non-capital functions relieving strategy in Beijing on air quality, and uncover possible improvements. To this end, based on the daily air quality and meteorological data of Beijing from January to April in 2019 and 2020, we used the difference in difference (DID) model [34] to identify the effects of industrial structure on air quality by taking the pandemic as a natural experiment. This paper offers some important insights: firstly, we conducted comparative research based on the assumption that the pandemic provided a quasi-experiment to estimate the outcome of industrial restructuring on air quality, which created a treated group. The use of DID effectively alleviates the endogenous problems such as the correlation between error terms and explanatory variables caused by missing variables, which provides evidence for accurately identifying the impact of industrial structure on air quality. Secondly, we specifically analyzed the heterogeneity of the five pollutants affected by industrial adjustments and found that limiting production is not an effective way to control ozone pollution. Thirdly, we evaluated the effectiveness of non-capital functions relieving strategy in Beijing, aimed at providing a reference for the future improvement of the policy. These could also be general lessons for other countries to probably learn from existing evidence in Beijing air governance.

The rest of the paper presents the methodology and data (Section 2), empirical results (Section 3), and robust test (Section 4). Finally, we conclude in Section 5.

\section{Methodology and Data}

\subsection{Variables and Data}

The air pollution variables are measured by air quality index (AQI) which is calculated by five air pollutants, including $\mathrm{SO}_{2}, \mathrm{PM}_{10}, \mathrm{PM}_{2.5}, \mathrm{CO}, \mathrm{NO}_{2}$, and $\mathrm{O}_{3}$ [35-37]. AQI focuses on assessing the health effects of breathing polluted air for hours, and AQI presents six pollutants with unified evaluation standards. Therefore, we extracted the hourly data of AQI from January to April in 2019 and 2020 in Beijing (pek), and then calculated the daily average. It was obtained from the China Environmental Monitoring Center by weighting data from 24 monitoring stations in Beijing (the spatial distribution of stations is shown in Appendix A Figure A1). The ready dispersal of air pollution $[38,39]$ determines that the control of the air quality depends not only on the emission reduction in a city but also on the pollutant control from the surrounding areas [40-42]. Therefore, Beijing's air quality may also be affected by the air quality of surrounding areas. We extracted the hourly data of AQI from January to April in 2019 and 2020 in Hebei Province, namely Baoding (bad), Chengde (chd), Langfang (laf), Zhangiiakou (zjk), Shijiazhuang (sjz), Tangshan (tas), Qinghuangdao (qhd), Handan (had), Cangzhou (caz), Hengshui (hes), and Xingtai (xit), and then calculated the daily average (NEIA). In order to analyze the heterogeneity of the impact that affects different pollutants, we used $\mathrm{PM}_{2.5}, \mathrm{O}_{3}, \mathrm{NO}, \mathrm{CO}$, and $\mathrm{SO}_{2}$ as alternative indicators. The data was from China Environmental Monitoring Center (http:/ / www.cnemc.cn/ accessed on 25 November 2021).

In the existing research, the industrial proportion has been used as the measurement index of industrial structure [43], but in fact, the adjustment of industrial structure should also consider the industrial profit, which can also reflect the industry restructuring. Therefore, we respectively used the profits of the secondary and tertiary industries in Beijing as the proxy variable to measure the industrial structure (TECP, TERP) of Beijing aimed at 
more accurate research results. The data was from Beijing Municipal Bureau of Statistics (http:/ / tjj.beijing.gov.cn/ accessed on 30 September 2021).

We used the daily passenger flow of Beijing Subway to represent the number of people choosing public transport in Beijing (passen). According to the statistics of the "Beijing Transport Development Annual Report", the passenger flow of Beijing rail transit was 3.85 billion passengers in 2018 [44]. The subway is one of the main public transportation methods for residents in Beijing. The data was from the daily passenger flow information published on the official Weibo website of Beijing Subway (available online at https:// weibo.com/bjsubway accessed on 8 October 2021).

In order to ensure the accuracy of the research results, we used meteorological data as control variables. Some air pollutants are water soluble; thus, rain may be one of the factors affecting air quality. Therefore, we chose the depth of liquid precipitation that is measured over a six-hour accumulation period to measure the rainfall (rain). Because of the flowing air, the wind can bring air pollutants from other areas or take local air pollutants away. We chose the rate of horizontal travel of air past a fixed point to measure the wind speed (speed). The ground temperature may accelerate the natural source emission or decomposition of precursors (such as VOCs) of some air pollution components (such as $\mathrm{O}_{3}$ ) [45]. Therefore, we chose temperature (temp) as one of the control variables. The previous study shows that the air qualities in northern China had a prominent correlation with the pressure [46]. Therefore, we chose atmospheric pressure (pressure) as a control variable. We extracted hourly meteorological data such as wind speed from Beijing Meteorological Station (No. 545110), and then calculated the daily average, obtaining the daily data from China Meteorological Administration (http:/ / www.cma.gov.cn/2011qxfw/2011qsjcx/ accessed on 15 October 2021).

In addition, this paper used multiple imputation, based on five replications and a chained equation approach method in the R multiple imputation procedure, to account for missing data $[47,48]$.

\subsection{Methodology}

Previous literature on the relationship between industrial structure and environmental pollution is mainly based on OLS [49], threshold model [15], and SGVAR model [43], but they cannot solve the interference of missing variables, which will cause errors in the consistent estimation of parameters. It is always a difficult problem to effectively deal with the identification deviation caused by endogeneity. DID is a measurement method specially used for policy effect evaluation, which regards the implementation of the new policy as an exogenous experiment. As it is more and more mature, the DID model is gradually widely used in many fields. The DID model is able to reduce the problems of endogenous problems [50,51]. The pandemic can be seen as a quasi-experiment [29]. Compared with the traditional model, the research results by DID are more accurate and reliable [52]. Therefore, taking Beijing as an example, we constructed a natural experiment and used the DID model to identify the impact of industrial structure on urban air quality, and evaluated the implementation effect of non-capital functions relieving strategy in Beijing.

In order to estimate the impact of urban industrial structure on air quality, we used DID regression based on the daily data of air quality, meteorology, and industrial statistics in Beijing. This paper divided the data from January to April in 2019 and 2020 into the control group and the treated group. And we defined that the year with COVID-19 pandemic (2020) was the treated group, and the year without COVID-19 (2019) was the control group. Then, according to the time of pandemic restrictions, the treated group was divided into prepandemic restrictions and post-pandemic restrictions, and the control group was divided, as well. Theoretically, there should be no significant difference in air quality between the treated group and the control group in January. Since February 2020, due to strict pandemic restrictions, the pandemic might change the industrial structure and then affect the air quality. Therefore, we took the samples from 1 January 2020 to 30 April 2020 as the treated group, and the samples from 1 January 2019 to 30 April 2019 as the control group, with a total of 241 samples. The data distribution is shown in Table 1. 
Table 1. The number of observations in the DID.

\begin{tabular}{cccc}
\hline & Before & After & Total \\
\hline Control & 31 & 89 & 120 \\
Treated & 31 & 90 & 121 \\
Total & 62 & 179 & 241 \\
\hline
\end{tabular}

Taking Beijing as an example, this paper used the DID model to analyze the impact of industrial structure adjustment on air quality. The model is set as follows:

$$
\begin{gathered}
Y_{t}=\beta+\beta_{1} \text { treated } \times T+\beta_{2} S E C P \times \text { treated } \times T+\beta_{3} T E R P \times \text { treated } \times T \\
+\beta_{4} S E C P+\beta_{5} T E R P+\beta_{6} \text { passen }+\beta_{7} N E I A+\beta_{8} \text { speed }+\beta_{9} \text { rain } \\
+\beta_{10} \text { temp }+\beta_{11} \text { pressure }+\beta_{12} \text { treated }+\beta_{13} T+\lambda_{t}+\varepsilon_{t}
\end{gathered}
$$

where $Y_{t}$ represents the interpreted variable, namely AQI (subscript $t$ represents time series), $\mathrm{PM}_{2.5}, \mathrm{O}_{3}, \mathrm{NO}, \mathrm{CO}, \mathrm{SO}_{2}$; SECP and TERP represent the industrial structure, SECP is the secondary industry profit and TERP is the tertiary industry profit; passen is the number of people choosing public transport; NEIA represents average AQI or specific pollutants of cities in Hebei Province; speed represents the rate of horizontal travel of air past a fixed point; rain is the depth of liquid precipitation that is measured over a six-hour accumulation period; temp is the daily temperature; pressure is the atmospheric pressure; $\lambda_{t}$ is the fixed effect, and $\varepsilon_{t}$ is the random error.

treated is a dummy variable, indicating whether the research object is the treated group.

$$
\text { treated }=\left\{\begin{array}{l}
1, \text { if } \text { year } \in 2020 \\
0, \text { if year } \in 2019
\end{array}\right.
$$

$T$ is a treated period dummy variable, that is, only the treated group would be impacted by the policy during the treated period. On 23 January 2020, Wuhan announced closure of the city. From 24 January to 30 January, Chinese provinces successively announced strict control measures for the pandemic, which happened to be the Spring Festival holiday. In view of the general shutdown during the Spring Festival holiday over the years, the industrial restructuring caused by the pandemic could not be shown during the Spring Festival holiday. Therefore, we assumed that the policy impact occurred after the Spring Festival, that is, the impact of the pandemic on industrial restructure and human activities actually began in February 2020.

$$
T=\left\{\begin{array}{l}
0, \text { if month } \leq 1 \\
1, \text { if month }>1
\end{array}\right.
$$

\section{Empirical Results}

\subsection{Descriptive Statistics}

Descriptive statistics were calculated for the 241 samples. As can be seen from Appendix A Table A1, the average value of AQI in Beijing is 76.69, which is defined as "moderate" by the Ministry of Ecology and Environment of China, indicating that air quality is acceptable overall but for some pollutants, there may be a moderate health concern for a very small number of people who are unusually sensitive to air pollution. Compared with the average value, the maximum of the AQI in Beijing is 256.38, relatively large, which is defined as "very unhealthy" in the Technical Regulation on Ambient Air Quality Index. At that time, everyone should avoid all outdoor exertion and may experience more serious health effects. The results of other pollutants are similar. The results of AQI are also very similar in Hebei Province, with a "moderate" average value (95.63) and a "very unhealthy" maximum (286.13). Therefore, the air pollution in Beijing must attract attention. 


\subsection{Analysis of Time Heterogeneity of Beijing Air Quality}

First, we compared the differences in air quality in Beijing before and after the pandemic. According to the results in Table 2, there was no significant difference in air quality in Beijing between January 2020 and January 2019. However, from February 2020 to April 2020, compared with February 2019 to April 2019, the average value of AQI decreased by 13.900, with the proportion similar to Bao and Zhang [53], which was significant at the level of $10 \%$. It shows that the pandemic has indeed affected the air quality in Beijing. However, it is a bit lower than 18.2 in the study of Chen et al. [54]; the possible reason is that he also considered 2018. The difference of mean change can only make a rough statistic of the impact of pandemic shutdown restriction policy on air quality. To estimate the specific effect, a more accurate regression statistical analysis is needed.

Table 2. Differences of AQI between January to April 2019 and January to April 2020.

\begin{tabular}{ccc}
\hline & $\mathbf{T}=\mathbf{0}$ & $\mathbf{T}=\mathbf{1}$ \\
\hline Treated group & 81.578 & 68.518 \\
Control group & 79.039 & 82.419 \\
Difference & 2.539 & $-13.900 *$ \\
\hline
\end{tabular}

\subsection{Basic Regression Estimation}

Initially, we tested the stationarity properties of the series using the augmented DickeyFuller (ADF) test. The maximum lag order was 21 [55]. The sequences of the variables were stationarity. To test for multicollinearity among the explanatory variables, we generated a matrix (Table 3), and the maximum and minimum variance inflation factor (VIF) values were less than 10 and not less than 0 , respectively. Therefore, it means there is no serious multicollinearity.

Table 3. Multicollinearity test results.

\begin{tabular}{ccc}
\hline Variable & VIF & 1/VIF \\
\hline SECP $\times$ treated $\times \mathrm{T}$ & 3.98 & 0.25 \\
TERP $\times$ treated $\times \mathrm{T}$ & 4.96 & 0.2 \\
SECP & 1.92 & 0.52 \\
TERP & 4.94 & 0.2 \\
passenger & 3.09 & 0.32 \\
NEIA & 1.29 & 0.78 \\
speed & 1.08 & 0.93 \\
rain & 1.11 & 0.9 \\
temperature & 2.81 & 0.36 \\
pressure & 1.96 & 0.51 \\
\hline
\end{tabular}

In order to investigate the impact of industrial structure on air quality in Beijing, we performed OLS regression based on 241 samples of air quality, meteorology, and industrial statistics in Beijing. The regression results are shown in Table 4.

According to the results in Table 4, the profit of the secondary industry in Beijing would strongly increase the air quality at the level of $1 \%$ significant level (0.257), almost 30 times that of the tertiary industry (0.007). It shows that the development of the secondary industry would worsen the air quality in Beijing, and it provides support for the non-capital functions relieving strategy in Beijing. The profit of the tertiary industry also has a positive impact on air quality, which is similar to the result found by He et al. [56]. In order to alleviate the urban disease in Beijing, the secondary industry should gradually transfer away from Beijing, which is consistent with the current industrial policy. 
Table 4. OLS estimation results of industrial adjustment on air quality.

\begin{tabular}{|c|c|c|c|c|c|c|}
\hline Variable & AQI & $\mathbf{P M}_{2.5}$ & $\mathrm{O}_{3}$ & $\mathrm{NO}_{2}$ & $\mathrm{CO}$ & $\mathrm{SO}_{2}$ \\
\hline SECP & $\begin{array}{c}0.257^{* * *} \\
(0.048)\end{array}$ & $\begin{array}{c}0.205^{* * *} \\
(0.041)\end{array}$ & $\begin{array}{l}-0.029 \\
(0.018)\end{array}$ & $\begin{array}{c}0.037^{* * *} \\
(0.014)\end{array}$ & $\begin{array}{c}0.002^{* * *} \\
(0.000)\end{array}$ & $\begin{array}{l}0.006^{*} \\
(0.003)\end{array}$ \\
\hline TERP & $\begin{array}{c}0.007^{* * *} \\
(0.002)\end{array}$ & $\begin{array}{c}0.005^{* * *} \\
(0.002)\end{array}$ & $\begin{array}{l}-0.001 \\
(0.001)\end{array}$ & $\begin{array}{c}0.0014^{* *} \\
(0.0006)\end{array}$ & $\begin{array}{l}0.00003^{* *} \\
(0.000015)\end{array}$ & $\begin{array}{c}0.000005 \\
(0.0001)\end{array}$ \\
\hline passen & $\begin{array}{c}-0.033^{* * *} \\
(0.006)\end{array}$ & $\begin{array}{c}-0.026^{* * *} \\
(0.005)\end{array}$ & $\begin{array}{c}0.001 \\
(0.002)\end{array}$ & $\begin{array}{l}-0.001 \\
(0.002)\end{array}$ & $\begin{array}{c}-0.0002 * * * \\
(0.000)\end{array}$ & $\begin{array}{c}-0.001 \\
(0.000)\end{array}$ \\
\hline NEIA & $\begin{array}{c}0.886^{* * *} \\
(0.046)\end{array}$ & $\begin{array}{c}0.839^{* * *} \\
(0.045)\end{array}$ & $\begin{array}{c}0.965^{* * *} \\
(0.038)\end{array}$ & $\begin{array}{c}1.013^{* * *} \\
(0.045)\end{array}$ & $\begin{array}{c}0.733^{* * *} \\
(0.033)\end{array}$ & $\begin{array}{c}0.360 * * * \\
(0.019)\end{array}$ \\
\hline speed & $\begin{array}{c}0.378 \\
(1.593)\end{array}$ & $\begin{array}{l}-0.485 \\
(1.330)\end{array}$ & $\begin{array}{c}0.390 \\
(0.472)\end{array}$ & $\begin{array}{c}-0.919 \text { * } \\
(0.475)\end{array}$ & $\begin{array}{l}-0.002 \\
(0.012)\end{array}$ & $\begin{array}{l}-0.115 \\
(0.104)\end{array}$ \\
\hline rain & $\begin{array}{l}-2.572 \\
(1.856)\end{array}$ & $\begin{array}{c}-3.195^{* *} \\
(1.547)\end{array}$ & $\begin{array}{l}1.413^{* *} \\
(0.548)\end{array}$ & $\begin{array}{c}-1.435^{* *} \\
(0.554)\end{array}$ & $\begin{array}{c}-0.042^{* * *} \\
(0.014)\end{array}$ & $\begin{array}{c}-0.221 \\
(0.121)\end{array}$ \\
\hline temp & $\begin{array}{c}0.827 \\
(0.422)\end{array}$ & $\begin{array}{c}0.571 \\
(0.352)\end{array}$ & $\begin{array}{c}-0.340^{* * *} \\
(0.125)\end{array}$ & $\begin{array}{c}0.481^{* * *} \\
(0.130)\end{array}$ & $\begin{array}{c}0.010 * * * \\
(0.003)\end{array}$ & $\begin{array}{c}0.009 \\
(0.028)\end{array}$ \\
\hline pressure & $\begin{array}{l}-0.078 \\
(0.432)\end{array}$ & $\begin{array}{l}-0.305 \\
(0.361)\end{array}$ & $\begin{array}{l}-0.047 \\
(0.128)\end{array}$ & $\begin{array}{c}-0.072 \\
(0.130)\end{array}$ & $\begin{array}{l}-0.002 \\
(0.003)\end{array}$ & $\begin{array}{l}-0.031 \\
(0.028)\end{array}$ \\
\hline constant & $\begin{array}{c}59.361 \\
(444.956)\end{array}$ & $\begin{array}{c}300.313 \\
(371.936)\end{array}$ & $\begin{array}{c}50.535 \\
(131.233)\end{array}$ & $\begin{array}{c}66.054 \\
(133.837)\end{array}$ & $\begin{array}{c}2.224 \\
(3.357)\end{array}$ & $\begin{array}{c}31.049 \\
(29.026)\end{array}$ \\
\hline $\mathrm{R}^{2}$ & 0.631 & 0.639 & 0.847 & 0.749 & 0.736 & 0.647 \\
\hline
\end{tabular}

Next, we analyzed the impact of the five pollutants by the industrial structure. SECP (0.205) and TERP (0.005) have a positive effect on $\mathrm{PM}_{2.5}$ at a significant level of $1 \%$, where the impact of SECP is more than 40 times that of TERP. The increase of the second industry significantly increases $\mathrm{PM}_{2.5}$ in Beijing. The concentration of $\mathrm{O}_{3}$ is also significantly affected by the industrial structure, with the fact that SECP $(0.037)$ is nearly 25 times higher than TERP $(0.0014)$. The increase in SECP would also cause an increase in CO at a significant level of $1 \%$, which is more than 50 times that of TERP. However, $\mathrm{O}_{3}$ and $\mathrm{SO}_{2}$ are not significantly affected by the industrial structure. The possible reason is that the implicit assumptions of OLS are too strict and inconsistent with reality, so the results may not be accurate. Therefore, we used the DID model to measure the impact of industrial structure on air quality more precisely.

\subsection{DID Estimation}

\subsubsection{Parallel Trend Test}

To more accurately verify the changes of air quality in Beijing before and after the shutdown caused by the pandemic, we constructed a natural experiment and used DID estimation to analyze, based on 241 samples from January to April in 2019 and 2020. An important premise for the effective application of DID method is to meet the parallel trend hypothesis, that is, without the shutdown caused by the pandemic, changes in the treated group (2020) are in line with the control group (2019), so that the average treatment effect obtained will not have estimation error caused by the periodic change of the sample itself. Therefore, we used Coefplot to carry out the parallel trend test. The test results shown in Figure 1 reveal that the coefficient does fluctuate around 0 before the outbreak, and the coefficient is negative after the outbreak shutdown, which demonstrates that the shutdown caused by the pandemic has alleviated air pollution. Thus, it can be determined that the sample data used in this paper meet the ex-ante parallel trend hypothesis. 


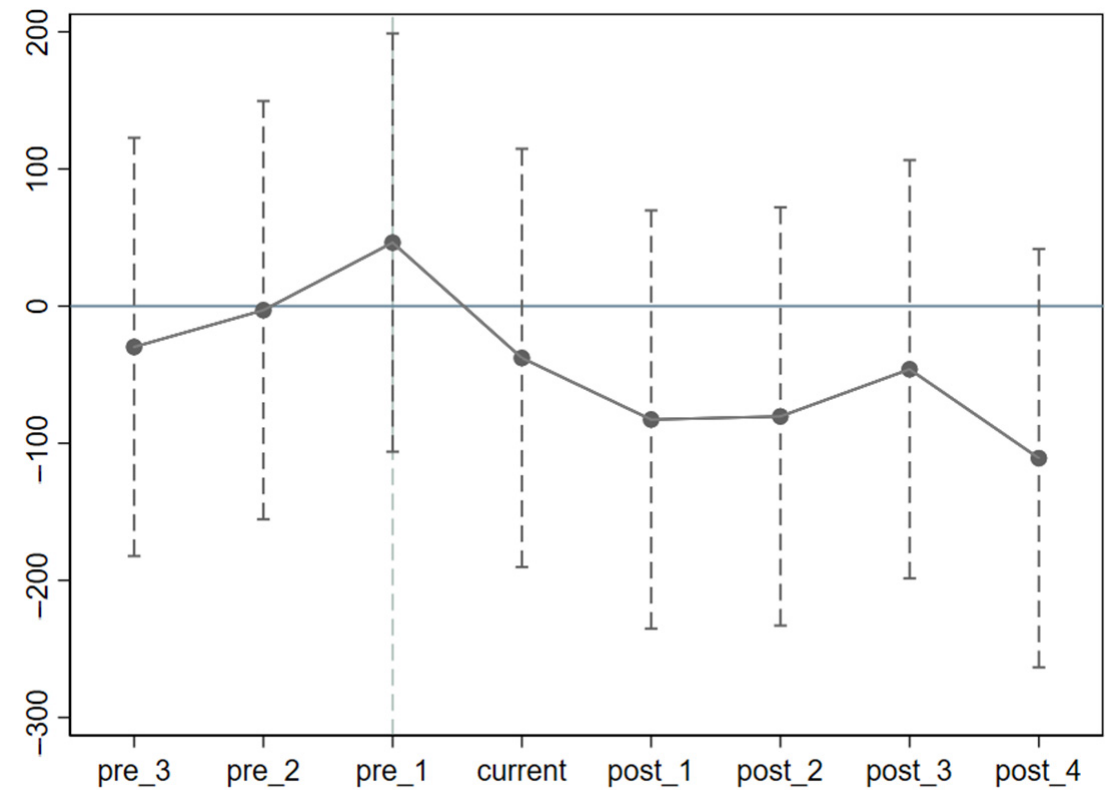

Figure 1. Parallel trend test.

\subsubsection{Regression Results of DID}

Table 5 shows the estimation results of the DID model. The coefficient of treated $\times \mathrm{T}$, which is most important, is 58.558 and significant at the level of $1 \%$. It shows that the change of industrial structure brought about by the pandemic does have a significant impact on Beijing's air quality. The coefficient of SECP (0.405) is more than ten times that of TERP $(0.034)$, which is significant at the level of $1 \%$, reflecting that the impact of the secondary industry profit on air quality is much higher than that of the tertiary industry. Thus, the secondary industry is the main factor affecting air quality and causing air pollution. Therefore, it is very necessary for Beijing to transform its industrial focus from the secondary industry to the tertiary industry, which is also in line with previous studies $[57,58]$. Interaction item SECP $\times$ treated $\times \mathrm{T}$ also has a significant negative effect on AQI $(-0.365)$ at the level of $1 \%$ and is much greater than the coefficient of the interaction term TERP $\times$ treated $\times \mathrm{T}(-0.031)$. It indicates that the pandemic has reduced the production of both the secondary and tertiary industries in Beijing, which has significantly improved the air quality in Beijing. Moreover, the effect of the reduction of the secondary industry on the improvement of air quality is better than that of the tertiary industry. Therefore, the implementation of the non-capital functions relieving strategy in Beijing is very timely and reasonable, and the industrial restructuring is effective and significant to the improvement of air quality.

The regression results of the control variables indicate that passen has a significant negative impact on AQI (-0.034), which means that if more people chose public transport, the air quality would be better. The air quality of Hebei Province also has a significant positive impact on Beijing. An increase of $1 \%$ on the average AQI in Hebei Province will lead to a rise of $0.978 \%$ on AQI in Beijing. It shows that as Hebei is a key area to undertake Beijing's industry, the deterioration of its air quality will also bring pressure to Beijing's atmospheric environment. Thus, the air quality in the surrounding areas is also very important, which is consistent with the result of Tao et al. [29]. If the non-capital functions relieving strategy in Beijing only relieves Beijing's secondary industry to the surrounding areas, it will not be able to maximize the effect of the policy, which may show the shortcomings of the current strategy. Different from the research results of Yu et al. [43], we find that the increase of wind speed will lead to the increase of AQI, which may be due to the fact that Hebei has already undertaken many manufacturing industries [59]. Therefore, the greater the regional wind speed is, the greater the impact of air quality in surrounding areas such as Hebei on Beijing will be. 
Table 5. DID regression results of industrial adjustment on AQI.

\begin{tabular}{|c|c|}
\hline Variable & AQI \\
\hline treated $\times \mathrm{T}$ & $\begin{array}{l}58.558^{* * *} \\
(12.810)\end{array}$ \\
\hline $\mathrm{SECP} \times$ treated $\times \mathrm{T}$ & $\begin{aligned}-0.365^{* * *} & (0.107)\end{aligned}$ \\
\hline TERP $\times$ treated $\times \mathrm{T}$ & $\begin{aligned}-0.031^{* * *} \\
(0.006)\end{aligned}$ \\
\hline SECP & $\begin{array}{c}0.405^{* * *} \\
(0.063)\end{array}$ \\
\hline TERP & $\begin{array}{c}0.034^{* * *} \\
(0.006)\end{array}$ \\
\hline passen & $\begin{aligned}-0.034^{* * *} & (0.010)\end{aligned}$ \\
\hline NEIA & $\begin{array}{c}0.988^{* * *} \\
(0.045)\end{array}$ \\
\hline speed & $\begin{array}{l}0.571 * \\
(0.344)\end{array}$ \\
\hline rain & $\begin{array}{c}-1.774 \\
(1.666)\end{array}$ \\
\hline temp & $\begin{array}{c}0.653 \\
(0.599)\end{array}$ \\
\hline pressure & $\begin{array}{l}-0.075 \\
(0.407)\end{array}$ \\
\hline treated & $\begin{array}{l}24.313^{* * *} \\
(8.819)\end{array}$ \\
\hline $\mathrm{T}$ & $\begin{array}{l}-9.678 \\
(10.046)\end{array}$ \\
\hline constant & $\begin{array}{c}-1.324 \\
(421.249)\end{array}$ \\
\hline$\lambda_{t}$ & control \\
\hline $\mathrm{R} 2$ & 0.717 \\
\hline
\end{tabular}

Note: ${ }^{* * *} p<0.01,{ }^{*} p<0.10$.

\subsubsection{Heterogeneity Analysis of Five Pollutants}

We further analyzed whether there was heterogeneity in the impact of industrial adjustment caused by the pandemic on different pollutants. According to Table 6, the effects of the variables treated $\times \mathrm{T}$ on $\mathrm{PM}_{2.5}, \mathrm{NO}_{2}$, and $\mathrm{CO}$ are 48.979, 11.928, and 0.303, respectively, at the significance level of $1 \%$. It shows that the pandemic does affect $\mathrm{PM}_{2.5}$, $\mathrm{NO}_{2}, \mathrm{CO}$. The increase of SECP and TERP will significantly aggravate these pollutants such as $\mathrm{PM}_{2.5}, \mathrm{NO}_{2}$, and $\mathrm{CO}$, which is in line with Pei et al. [60] and Xue et al. [61]. Combined with the previous OLS model results, the regression coefficient of SECP is the biggest on $\mathrm{PM}_{2.5}$ (0.332) among the five pollutants, which means that $\mathrm{PM}_{2.5}$ is affected most seriously by the second industry. Interaction item SECP $\times$ treated $\times \mathrm{T}$ also has a significant negative effect on $\mathrm{PM}_{2.5}(-0.303), \mathrm{NO}_{2}(-0.106)$, and $\mathrm{CO}(-0.002)$ at the level of $5 \%$. It shows that the shutdown of the secondary industry has a significant impact on the improvement of the air quality, which is greater than that of the tertiary industry.

The impact of the pandemic shutdown on $\mathrm{SO}_{2}$ is not very significant. The main reason may be that the main sources affecting $\mathrm{SO}_{2}$ concentration in Beijing are the heating boiler and the general industrial boiler [11]. The heating industry is affected by temperature and has little correlation with the pandemic and the adjustment of industrial structure. Therefore, it is reasonable that the impact of the shutdown on $\mathrm{SO}_{2}$ is not significant. The coefficients of SECP, TERP, SECP $\times$ treated $\times \mathrm{T}$, and TERP $\times$ treated $\times \mathrm{T}$ on $\mathrm{O}_{3}$ are opposite and significant compared to other types of pollutants. There are also several possible reasons. Researchers found that a decrease in $\mathrm{PM}_{2.5}$ can lead to an increase in the $\mathrm{O}_{3}$ concentration $[62,63]$ because $\mathrm{PM}_{2.5}$ can eliminate the precursors of ozone, including hydroxyl radicals and nitrogen-oxygen free radicals $[64,65]$. When the $\mathrm{PM}_{2.5}$ concentration 
falls, the concentrations of hydroxyl radicals and nitrogen-oxygen free radicals in the air will increase, thereby promoting the production of ozone [66]. Furthermore, as $\mathrm{PM}_{2.5}$ decreases, the higher amount of solar radiation would reach the near-surface air, thereby accelerating the photochemical reactions involved in ozone production, so more $\mathrm{O}_{3}$ would be produced [67].

Table 6. DID regression results of industrial adjustment on specific pollutants.

\begin{tabular}{|c|c|c|c|c|c|}
\hline Variable & $\mathbf{P M}_{2.5}$ & $\mathrm{O}_{3}$ & $\mathrm{NO}_{2}$ & $\mathrm{CO}$ & $\mathrm{SO}_{2}$ \\
\hline \multirow[t]{2}{*}{ treated $\times \mathrm{T}$} & $48.979 * * *$ & -4.674 & $11.928 * * *$ & $0.303^{* * *}$ & -0.834 \\
\hline & (10.819) & $(3.927)$ & (4.035) & $(0.101)$ & $(0.936)$ \\
\hline \multirow[t]{2}{*}{$\mathrm{SECP} \times$ treated $\times \mathrm{T}$} & $-0.303^{* * *}$ & $0.092 * * *$ & $-0.106^{* * *}$ & $-0.002 * *$ & -0.005 \\
\hline & $(0.090)$ & $(0.033)$ & $(0.034)$ & $(0.001)$ & $(0.008)$ \\
\hline \multirow[t]{2}{*}{$\mathrm{TERP} \times$ treated $\times \mathrm{T}$} & $-0.024^{* * *}$ & $0.006^{* * *}$ & $-0.006^{* * *}$ & $-0.0002^{* * *}$ & -0.0001 \\
\hline & $(0.005)$ & $(0.002)$ & $(0.002)$ & $(0.00005)$ & $(0.0004)$ \\
\hline \multirow[t]{2}{*}{ SECP } & $0.332^{* * *}$ & $-0.069^{* * *}$ & $0.071^{* * *}$ & $0.003^{* * *}$ & 0.008 \\
\hline & $(0.053)$ & $(0.021)$ & $(0.020)$ & $(0.001)$ & $(0.005)$ \\
\hline \multirow[t]{2}{*}{ TERP } & $0.027^{* * *}$ & $-0.006^{* * *}$ & $0.006^{* * *}$ & $0.0002^{* * *}$ & 0.00002 \\
\hline & $(0.005)$ & $(0.002)$ & $(0.002)$ & $(0.00005)$ & $(0.0004)$ \\
\hline \multirow{2}{*}{ passen } & $-0.023^{* * *}$ & $0.009 * * *$ & $-0.006 *$ & $-0.0002 * * *$ & -0.002 * \\
\hline & $(0.008)$ & $(0.003)$ & $(0.003)$ & $(0.00008)$ & $(0.001)$ \\
\hline \multirow[t]{2}{*}{ NEIA } & $0.949^{* * *}$ & $1.056^{* * *}$ & $1.103^{* * *}$ & $0.822 * * *$ & $0.371^{* * *}$ \\
\hline & $(0.044)$ & $(0.045)$ & $(0.048)$ & $(0.036)$ & $(0.025)$ \\
\hline \multirow[t]{2}{*}{ speed } & -0.273 & 0.044 & -0.776 * & 0.004 & -0.092 \\
\hline & $(1.230)$ & $(0.453)$ & $(0.462)$ & $(0.012)$ & $(0.107)$ \\
\hline \multirow[t]{2}{*}{ rain } & $-2.339 *$ & $1.413^{* * *}$ & $-1.262^{* * *}$ & $-0.037^{* * *}$ & -0.223 \\
\hline & $(1.408)$ & $(0.517)$ & $(0.530)$ & $(0.013)$ & $(0.123)$ \\
\hline \multirow[t]{2}{*}{ temp } & 0.479 & -0.076 & $0.349^{* * *}$ & 0.006 & -0.012 \\
\hline & $(0.506)$ & $(0.187)$ & $(0.190)$ & $(0.005)$ & $(0.044)$ \\
\hline \multirow[t]{2}{*}{ pressure } & -0.244 & 0.003 & -0.092 & -0.003 & -0.030 \\
\hline & $(0.344)$ & $(0.126)$ & $(0.130)$ & $(0.003)$ & $(0.030)$ \\
\hline \multirow[t]{2}{*}{ treated } & $21.153^{* * *}$ & $-5.951^{* *}$ & 3.400 & $0.154^{* *}$ & 0.731 \\
\hline & (7.459) & (2.999) & $(2.854)$ & $(0.071)$ & $(0.721)$ \\
\hline \multirow[t]{2}{*}{$\mathrm{T}$} & -7.463 & -3.416 & -0.397 & 0.030 & 0.572 \\
\hline & $(8.483)$ & $(3.138)$ & $(3.232)$ & $(0.082)$ & $(0.785)$ \\
\hline \multirow[t]{2}{*}{ constant } & 187.800 & 0.677 & 76.987 & 2.071 & 30.441 \\
\hline & (356.309) & $(130.863)$ & (134.804) & $(3.356)$ & (31.131) \\
\hline$\lambda_{t}$ & control & control & control & control & control \\
\hline $\mathrm{R} 2$ & 0.715 & 0.871 & 0.781 & 0.773 & 0.653 \\
\hline
\end{tabular}

\section{Robust Test}

\subsection{Placebo Test}

The placebo test is one of the most commonly used robustness test methods in the DID model. In order to test whether the improvement of air quality is really caused by the impact of the shutdown, we made up the time node of the pandemic impact. The dates 10 January and 20 February 2020 are selected as fictitious nodes for regression. Table 7 shows that the estimated coefficients in both variables are not significant; thus, the pandemic shutdown did not play a role after the virtual time point, and the placebo test passed. It implies that after the Spring Festival in 2020, the air quality in Beijing has improved compared with the same period in 2019, which is indeed caused by the industrial changes brought about by the pandemic. Therefore, it can be considered that the research results of this paper are robust, and the conclusion is reliable.

\subsection{Data Robust Test}

Aimed at eliminating the specific regression results due to the particularity of the data, we used the daily data during 2019 2021 to replace the data from January to April in 2019 and 2020 for regression analysis. The method and other data are consistent with the previous regression. The DID regression results shown in Table 8 are roughly consistent with the main explanatory variables in Table $5(\mathrm{SECP} \times$ treated $\times \mathrm{T}$, TERP $\times$ treated $\times \mathrm{T})$. Thus, it can be considered that the research results of this paper are robust, and the conclusion is reliable. 
Table 7. Placebo test results.

\begin{tabular}{|c|c|c|}
\hline Variable & Shock on 10 January 2020 & Shock on 20 February 2020 \\
\hline \multirow[t]{2}{*}{ treated $\times \mathrm{T}$} & 10.803 & 18.497 \\
\hline & $(15.887)$ & $(21.436)$ \\
\hline \multirow{2}{*}{$\mathrm{SECP} \times$ treated $\times \mathrm{T}$} & $-0.173^{* * *}$ & -0.238 \\
\hline & $(0.097)$ & $(0.166)$ \\
\hline \multirow{2}{*}{$\mathrm{TERP} \times$ treated $\times \mathrm{T}$} & $-0.029^{* * *}$ & $-0.027^{* * *}$ \\
\hline & $(0.005)$ & $(0.007)$ \\
\hline \multirow[t]{2}{*}{ SECP } & $0.361^{* * *}$ & $0.340 * * *$ \\
\hline & $(0.057)$ & $(0.096)$ \\
\hline \multirow[t]{2}{*}{ TERP } & $0.031^{* * *}$ & $0.030 * * *$ \\
\hline & $(0.005)$ & $(0.007)$ \\
\hline \multirow[t]{2}{*}{ passen } & $-0.047^{* * *}$ & $-0.046^{* * *}$ \\
\hline & $(0.010)$ & $(0.010)$ \\
\hline \multirow{2}{*}{ NEIA } & $0.945^{* * *}$ & $0.949^{* * *}$ \\
\hline & $(0.044)$ & $(0.045)$ \\
\hline \multirow[t]{2}{*}{ speed } & 0.739 & 0.684 \\
\hline & $(1.471)$ & $(1.469)$ \\
\hline \multirow[t]{2}{*}{ rain } & -2.322 & -2.309 \\
\hline & $(1.716)$ & $(1.714)$ \\
\hline \multirow[t]{2}{*}{ temp } & 0.684 & 0.710 \\
\hline & $(0.479)$ & $(0.467)$ \\
\hline \multirow[t]{2}{*}{ pressure } & 0.028 & 0.025 \\
\hline & $(0.409)$ & $(0.409)$ \\
\hline \multirow[t]{2}{*}{ treated } & $35.346^{* *}$ & $31.598^{* * *}$ \\
\hline & $(14.193)$ & $(10.416)$ \\
\hline \multirow[t]{2}{*}{$\mathrm{T}$} & 4.123 & 4.017 \\
\hline & (11.014) & $(11.953)$ \\
\hline \multirow[t]{2}{*}{ constant } & -94.330 & -86.799 \\
\hline & $(424.447)$ & $(422.489)$ \\
\hline$\lambda_{t}$ & control & control \\
\hline $\mathrm{R} 2$ & 0.697 & 0.698 \\
\hline
\end{tabular}

Note: ${ }^{* * *} p<0.01,{ }^{* *} p<0.05$.

Table 8. Data robust test results.

\begin{tabular}{|c|c|}
\hline Variable & AQI \\
\hline treated $\times \mathrm{T}$ & $\begin{array}{c}12.654 * \\
(7.160)\end{array}$ \\
\hline $\mathrm{SECP} \times$ treated $\times \mathrm{T}$ & $\begin{array}{c}-0.042 * \\
(0.024)\end{array}$ \\
\hline $\mathrm{TERP} \times$ treated $\times \mathrm{T}$ & $\begin{array}{c}-0.002 * \\
(0.001)\end{array}$ \\
\hline SECP & $\begin{array}{l}0.043 * \\
(0.023)\end{array}$ \\
\hline TERP & $\begin{array}{c}0.001 \\
(0.001)\end{array}$ \\
\hline passen & $\begin{array}{c}-0.007^{* *} \\
(0.003)\end{array}$ \\
\hline NEIA & $\begin{array}{c}0.973^{* * *} \\
(0.022)\end{array}$ \\
\hline speed & $\begin{array}{c}1.664^{* *} \\
(0.660)\end{array}$ \\
\hline rain & $\begin{array}{l}-0.194 \\
(0.413)\end{array}$ \\
\hline temp & $\begin{array}{c}-0.354 \\
(0.143)\end{array}$ \\
\hline pressure & $\begin{array}{c}-0.340 \text { ** } \\
(0.155)\end{array}$ \\
\hline treated & $\begin{array}{r}-1.591 \\
(6.162)\end{array}$ \\
\hline $\mathrm{T}$ & $\begin{array}{c}36.882 * * * \\
(5.063)\end{array}$ \\
\hline constant & $\begin{array}{l}302.339 * \\
(160.059)\end{array}$ \\
\hline$\lambda_{t}$ & control \\
\hline $\mathrm{R} 2$ & 0.682 \\
\hline
\end{tabular}




\section{Conclusions}

Based on the opportunity provided by the pandemic, this study aims to clarify the impact of industrial restructuring on urban air quality, estimate the effects of non-capital functions relieving strategy in Beijing on air quality, and uncover possible improvements. The research results show that, first, the impact of profits of the secondary industry on air quality is ten times higher than that of the tertiary industry. Therefore, the secondary industry is the main factor causing air pollution. According to the fourth national economic census of Beijing in 2018, which is the latest one in China, the revenue of Beijing's secondary and tertiary industries totaled CNY 18,310.34 billion. Among them, the secondary industry is CNY 3846.84 billion, accounting for $21.01 \%$, while the tertiary industry is as high as CNY 14463.5 billion, accounting for $78.99 \%$. The tertiary industry has become the pillar of Beijing's economic development nowadays. It means the non-capital functions relieving strategy in Beijing has great progress. Second, the pandemic has reduced the production of both the secondary and tertiary industries in Beijing, which has significantly improved the air quality in Beijing. Moreover, the effect of the reduction in the secondary industry on the improvement of air quality is better than that of the tertiary industry. Therefore, it is very necessary for Beijing to transform its industrial focus from the secondary industry to the tertiary industry. In 2018, 13.61 million people were employed in the secondary and tertiary industries in Beijing. Among them, there were 2.036 million people in the secondary industry, accounting for $14.96 \%$, and 11.574 million people in the tertiary industry, accounting for $85.04 \%$. Therefore, the transformation from the secondary industry to the tertiary industry can not only relieve the pressure of air quality but also solve the problem of unemployment. Third, $\mathrm{PM}_{2.5}, \mathrm{NO}_{2}$, and $\mathrm{CO}$ are affected by the secondary and tertiary industries, where $\mathrm{PM}_{2.5}$ is affected most seriously by the second industry, and the shutdown of the secondary industry can bring greater benefits. Therefore, the implementation of the non-capital functions relieving strategy in Beijing is very timely and reasonable, and the adjustment of the industrial structure is effective and significant to the improvement of air quality. Fourth, the coefficients of $\mathrm{O}_{3}$ are opposite and significant compared to other types of pollutants. The probable reason is that the decrease of $\mathrm{PM}_{2.5}$ will lead to an increase in the concentration of $\mathrm{O}_{3}$. Fifth, the air quality of Hebei Province also has a significant positive impact on the air quality of Beijing, hence the aggravation of air pollution in Hebei will also bring pressure to Beijing's air quality control. Therefore, for the industrial adjustment in the process of air pollution control, reasonable planning of the region is very essential.

In the end, combined with the current situation of Beijing, we propose the following enlightenment to improve air quality: First, the implementation of the non-capital functions relieving strategy in Beijing is very timely. The policy promotes the adjustment of the industrial structure in Beijing and effectively alleviates air pollution. These could also be general lessons for other countries to probably learn from existing evidence in Beijing air governance. Second, although the shutdown and restriction policy can improve $\mathrm{PM}_{2.5}$, $\mathrm{NO}_{2}, \mathrm{CO}$, and other conventional pollutants, $\mathrm{O}_{3}$ pollution cannot be reduced. $\mathrm{O}_{3}$ can damage the respiratory tract and mucous membrane, without conventional protective methods to deal with. Therefore, it is urgent to formulate scientific methods to deal with $\mathrm{O}_{3}$ pollution. Last but not least, under the non-capital functions relieving strategy in Beijing, Hebei is regarded as a key area to undertake Beijing's transfer industries, while the air pollution in Hebei will also infect Beijing. Therefore, in the process of industrial adjustment, the selection of appropriate regions for undertaking industries is very vital. We will pay attention to that in the future.

Author Contributions: Conceptualization, C.T. and G.D.; methodology, C.T.; software, C.T. and G.D.; validation, Z.L.; formal analysis, C.T. and Z.L.; investigation, C.T.; resources, Z.L.; data curation, Z.L.; writing—original draft preparation, C.T.; writing—review and editing, M.H., B.C. and G.D.; visualization, B.C.; supervision, M.H. and B.C.; project administration, B.C.; funding acquisition, B.C. All authors have read and agreed to the published version of the manuscript. 
Funding: This research is funded by the National Natural Science Foundation of China (Grant No. 71873016); State Forestry and Grassland Administration (Grant No. 2019132707).

Institutional Review Board Statement: Not applicable.

Informed Consent Statement: Not applicable.

Data Availability Statement: All data used during the study are available from the corresponding author by request.

Conflicts of Interest: The authors declare no conflict of interest.

\section{Appendix A}

Table A1. Data characteristics.

\begin{tabular}{|c|c|c|c|c|c|c|}
\hline Variable & Description & Mean & p50 & sd & Min & $\operatorname{Max}$ \\
\hline AQI & Air quality index & 76.69 & 61.13 & 49.86 & 20.00 & 256.38 \\
\hline $\mathrm{PM}_{2.5}$ & $\mathrm{PM}_{2.5}$ concentration in the air & 52.79 & 53.96 & 22.87 & 7.13 & 166.92 \\
\hline $\mathrm{O}_{3}$ & Ozone concentration in the air & 34.10 & 30.63 & 18.04 & 3.67 & 99.88 \\
\hline $\mathrm{CO}$ & $\mathrm{CO}$ concentration in the air & 0.71 & 0.57 & 0.44 & 0.13 & 2.53 \\
\hline $\mathrm{NO}$ & NO concentration in the air & 5.42 & 4.33 & 3.32 & 1.96 & 21.67 \\
\hline $\mathrm{SO}_{2}$ & $\mathrm{SO}_{2}$ concentration in the air & 34.10 & 30.63 & 18.04 & 3.67 & 99.88 \\
\hline NEIA $_{\text {aqi }}$ & $\begin{array}{l}\text { The average AQI of cities in Hebei } \\
\text { including bad, chd, laf, zjk, sjz, tas, } \\
\text { qhd, had, caz, hes, xit }\end{array}$ & 95.625 & 81.545 & 47.724 & 25.841 & 286.125 \\
\hline
\end{tabular}

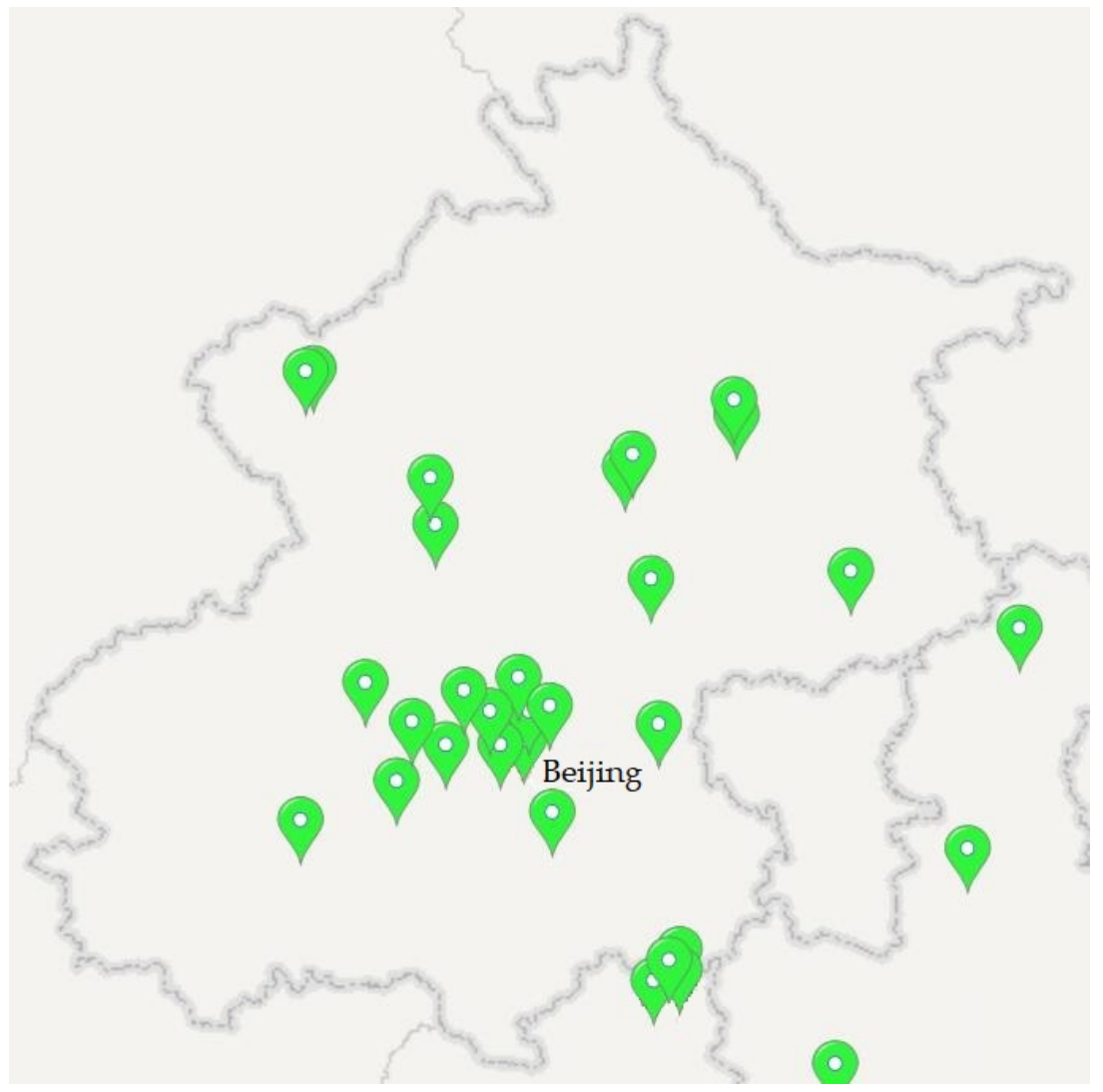

Figure A1. The spatial distribution of stations in Beijing (China Environmental Monitoring Center). 


\section{References}

1. Li, J.; Shi, X.; Wu, H.; Liu, L. Trade-off between economic development and environmental governance in China: An analysis based on the effect of river chief system. China Econ. Rev. 2019, 60, 101403. [CrossRef]

2. Tiba, S.; Omri, A. Literature survey on the relationships between energy, environment and economic growth. Renew. Sustain. Energy Rev. 2017, 69, 1129-1146. [CrossRef]

3. Andrée, B.P.J.; Chamorro, A.; Spencer, P.; Koomen, E.; Dogo, H. Revisiting the relation between economic growth and the environment; a global assessment of deforestation, pollution and carbon emission. Renew. Sustain. Energy Rev. 2019, 114, 109221. [CrossRef]

4. Zhang, Y.-J.; Liu, Z.; Zhang, H.; Tan, T.-D. The impact of economic growth, industrial structure and urbanization on carbon emission intensity in China. Nat. Hazards 2014, 73, 579-595. [CrossRef]

5. Zhou, X.; Zhang, J.; Li, J. Industrial structural transformation and carbon dioxide emissions in China. Energy Policy 2013, 57, 43-51. [CrossRef]

6. Wang, Y.; Guo, Z.; Han, J. The relationship between urban heat island and air pollutants and them with influencing factors in the Yangtze River Delta, China. Ecol. Indic. 2021, 129, 107976.

7. Hankey, S.; Marshall, J.D. Urban Form, Air Pollution, and Health. Curr. Environ. Health Rep. 2017, 4, 491-503.

8. Orru, H.; Ebi, K.L.; Forsberg, B. The Interplay of Climate Change and Air Pollution on Health. Curr. Environ. Health Rep. 2017, 4, 504-513. [CrossRef] [PubMed]

9. Fodha, M.; Zaghdoud, O. Economic growth and pollutant emissions in Tunisia: An empirical analysis of the environmental Kuznets curve. Energy Policy 2010, 38, 1150-1156. [CrossRef]

10. Liu, J.; Qu, J.; Zhao, K. Is China's development conforms to the Environmental Kuznets Curve hypothesis and the pollution haven hypothesis? J. Clean. Prod. 2019, 234, 787-796.

11. Xie, H.; Shen, M.; Wei, C. Technical efficiency, shadow price and substitutability of Chinese industrial $\mathrm{SO}_{2}$ emissions: $\mathrm{A}$ parametric approach. J. Clean. Prod. 2016, 112, 1386-1394. [CrossRef]

12. Park, S.; Lee, Y. Regional model of EKC for air pollution: Evidence from the Republic of Korea. Energy Policy 2011, 39, 5840-5849. [CrossRef]

13. Hou, J.; Teo, T.S.H.; Zhou, F.; Lim, M.K.; Chen, H. Does industrial green transformation successfully facilitate a decrease in carbon intensity in China? An environmental regulation perspective. J. Clean. Prod. 2018, 184, 1060-1071. [CrossRef]

14. Bai, Y.; Deng, X.; Jiang, S.; Zhang, Q.; Wang, Z. Exploring the relationship between urbanization and urban eco-efficiency: Evidence from prefecture-level cities in China. J. Clean. Prod. 2017, 195, 1487-1496. [CrossRef]

15. Zheng, Y.; Peng, J.; Xiao, J.; Su, P.; Li, S. Industrial structure transformation and provincial heterogeneity characteristics evolution of air pollution: Evidence of a threshold effect from China. Atmos. Pollut. Res. 2019, 11, 598-609. [CrossRef]

16. Jung, T.Y.; Park, T.S. Structural Change of the Manufacturing Sector in Korea: Measurement of Real Energy Intensity and $\mathrm{CO}_{2}$ Emissions. Mitig. Adapt. Strat. Glob. Chang. 2000, 5, 221-238. [CrossRef]

17. Shi, K.; Wu, L. Forecasting air quality considering the socio-economic development in Xingtai. Sustain. Cities Soc. 2020, 61, 102337. [CrossRef]

18. Grossman, G.M.; Krueger, A.B. Economic growth and the environment. Q. J. Econ. 1995, 110, $353-377$.

19. Zhu, L.; Tong, L.; Ma, L. Impact of industrial structure adjustment on smog pollution: An empirical study based on the Beijing-Tianjin-Hebei urban agglomeration. Ecol. Econ. 2018, 34, 141-148.

20. Guo, M.; Liu, Y.; Yu, H.; Hu, B.; Sang, Z. An overview of smart city in China. China Commun. 2016, 13, 203-211. [CrossRef]

21. Chan, C.K.; Yao, X. Air pollution in mega cities in China. Atmos. Environ. 2008, 42, 1-42. [CrossRef]

22. Zhao, B.; Xu, J.; Hao, J. Impact of energy structure adjustment on air quality: A case study in Beijing, China. Front. Environ. Sci. Eng. China 2011, 5, 378-390. [CrossRef]

23. Zhang, H.; Wang, S.; Hao, J.; Wang, X.; Wang, S.; Chai, F.; Li, M. Air pollution and control action in Beijing. J. Clean. Prod. 2015, 112, 1519-1527. [CrossRef]

24. Wang, M.; Ma, X.; Krstikj, A. The spatial pattern of MNCs headquarters in the context of developmental state: The case of Beijing. Habitat Int. 2021, 112, 102357. [CrossRef]

25. Liu, Z.; Chen, X.; Cai, J.; Baležentis, T.; Li, Y. The Impact of "Coal to Gas” Policy on Air Quality: Evidence from Beijing, China. Energies 2020, 13, 3876. [CrossRef]

26. Viard, V.B.; Fu, S. The effect of Beijing's driving restrictions on pollution and economic activity. J. Public Econ. 2015, 125, 98-115. [CrossRef]

27. Cao, J.; Wang, X.; Zhong, X. Did driving restrictions improve air quality in Beijing? China Econ. Q. 2014, 13, 1091-1126.

28. Li, T.; Liu, Y.; Wang, C.; Wang, Z. Environmental impact of Beijing's industrial decentralization based on a discrete choice modeling approach. J. Tsinghua Univ. (Sci. Technol.) 2017, 57, 1163-1169.

29. Tao, C.; Wheiler, K.; Yu, C.; Cheng, B.; Diao, G. Does the joint prevention and control regulation improve the air quality? A qua-si-experiment in the Beijing economic belt during the COVID-19 pandemic. Sustain. Cities Soc. 2021, 75, 103365.

30. Chen, Y.G.J.N. Identification of ecological corridors' spatial pattern in Beijing-Tianjin-Hebei region from the perspective of wind domain. China Environ. Sci. 2020, 41, 3418-3426.

31. Leung, K.; Wu, J.T.; Liu, D.; Leung, G. First-wave COVID-19 transmissibility and severity in China outside Hubei after control measures, and second-wave scenario planning: A modelling impact assessment. Lancet 2020, 395, 1382-1393. [CrossRef] [PubMed] 
32. Han, Y.; Yang, L.; Jia, K.; Li, J.; Feng, S.; Chen, W.; Zhao, W.; Pereira, P. Spatial distribution characteristics of the COVID-19 pandemic in Beijing and its relationship with environmental factors. Sci. Total Environ. 2020, 761, 144257. [CrossRef]

33. Zhang, Y.; Ma, Z.F. Impact of the COVID-19 Pandemic on Mental Health and Quality of Life among Local Residents in Liaoning Province, China: A Cross-Sectional Study. Int. J. Environ. Res. Public Health 2020, 17, 2381. [CrossRef]

34. Heckman, J.J.; Ichimura, H.; Todd, P.E. Matching As An Econometric Evaluation Estimator: Evidence from Evaluating a Job Training Programme. Rev. Econ. Stud. 1997, 64, 605-654. [CrossRef]

35. Tong, Z.; Chen, Y.; Malkawi, A.; Liu, Z.; Freeman, R.B. Energy saving potential of natural ventilation in China: The impact of ambient air pollution. Appl. Energy 2016, 179, 660-668. [CrossRef]

36. Kyrkilis, G.; Chaloulakou, A.; Kassomenos, P.A. Development of an aggregate Air Quality Index for an urban Mediterranean agglomeration: Relation to potential health effects. Environ. Int. 2007, 33, 670-676. [CrossRef]

37. Lian, X.; Huang, J.; Huang, R.-J.; Liu, C.; Wang, L.; Zhang, T. Impact of city lockdown on the air quality of COVID-19-hit of Wuhan city. Sci. Total Environ. 2020, 742, 140556. [CrossRef] [PubMed]

38. Henderson, J. Externalities in a spatial context. J. Public Econ. 1977, 7, 89-110. [CrossRef]

39. Zhang, Y.; Liu, C.; Chen, L.; Wang, X.; Song, X.; Li, K. Energy-related $\mathrm{CO}_{2}$ emission peaking target and path-ways for China's city: A case study of Baoding City. J. Clean. Prod. 2019, 226, 471-481.

40. Qin, M.; Wang, X.; Hu, Y.; Huang, X.; He, L.; Zhong, L.; Song, Y.; Hu, M.; Zhang, Y. Formation of particulate sulfate and nitrate over the Pearl River Delta in the fall: Diagnostic analysis using the Community Multiscale Air Quality model. Atmos. Environ. 2015, 112, 81-89. [CrossRef]

41. Wang, Y.; Li, Y.; Qiao, Z.; Lu, Y. Inter-city air pollutant transport in The Beijing-Tianjin-Hebei urban agglomeration: Comparison between the winters of 2012 and 2016. J. Environ. Manag. 2019, 250, 109520.

42. Zheng, G.J.; Duan, F.K.; Su, H.; Ma, Y.L.; Cheng, Y.; Zheng, B.; Zhang, Q.; Huang, T.; Kimoto, T.; Chang, D.; et al. Exploring the severe winter haze in Beijing: The impact of synoptic weather, regional transport and heterogeneous reactions. Atmospheric Chem. Phys. 2015, 15, 2969-2983. [CrossRef]

43. Yu, D.; Li, S.; Zhou, T. Industrial Structure Effect of China's Urban Air Quality Improvement: A Natural Experiment of COVID-19. J. Financ. Econ. 2021, 47, 19-34.

44. Beijing Transport Institute. Beijing Transport Development Annual Report. 2020. (In Chinese). Available online: http://www. bjtrc.org.cn/List/index/cid/7.html (accessed on 22 July 2021).

45. Yen, M.-C.; Peng, C.-M.; Chen, T.-C.; Chen, C.-S.; Lin, N.-H.; Tzeng, R.-Y.; Lee, Y.-A.; Lin, C.-C. Climate and weather characteristics in association with the active fires in northern Southeast Asia and spring air pollution in Taiwan during 2010 7-SEAS/Dongsha Experiment. Atmos. Environ. 2013, 78, 35-50. [CrossRef]

46. Chen, Z.H.; Cheng, S.Y.; Li, J.B.; Guo, X.R.; Wang, W.H.; Chen, D.S. Relationship between atmospheric pollution processes and synoptic pressure patterns in northern China. Atmos. Environ. 2008, 42, 6078-6087.

47. Su, Y.-S.; Gelman, A.; Hill, J.; Yajima, M. Multiple Imputation with Diagnostics (mi) inR: Opening Windows into the Black Box. J. Stat. Softw. 2011, 45, 1-31. [CrossRef]

48. Pei, J.; Wang, X.; Chen, P.; Zheng, K.; Hu, X. Hb Levels and Sex Differences in Relation to Short-Term Out-comes in Patients With Acute Myocardial Infarction. Front. Cardiovasc. Med. 2021, 8, 759.

49. Zheng, Z.; Bi, J.T.; Liu, Y.Q.; Cai, X. The impact of COVID-19 pandemic on the treatment of acute appendicitis in China. Int. J. Color. Dis. 2021, 1-5. [CrossRef]

50. Crabbe, J.C.; Metten, P.; Rhodes, J.S.; Yu, C.-H.; Brown, L.L.; Phillips, T.J.; Finn, D.A. A Line of Mice Selected for High Blood Ethanol Concentrations Shows Drinking in the Dark to Intoxication. Biol. Psychiatry 2009, 65, 662-670. [CrossRef]

51. Dong, F.; Dai, Y.; Zhang, S.; Zhang, X.; Long, R. Can a carbon emission trading scheme generate the Porter effect? Evidence from pilot areas in China. Sci. Total Environ. 2019, 653, 565-577. [PubMed]

52. Zhou, B.; Zhang, C.; Song, H.; Wang, Q. How does emission trading reduce China's carbon intensity? An ex-ploration using a decomposition and difference-in-differences approach. Sci. Total Environ. 2019, 676, 514-523.

53. Bao, R.; Zhang, A. Does lockdown reduce air pollution? Evidence from 44 cities in northern China. Sci. Total Environ. 2020, 731, 139052. [CrossRef] [PubMed]

54. Chen, G.; Tao, J.; Wang, J.; Dong, M.; Li, X.; Sun, X.; Cheng, S.; Fan, J.; Ye, Y.; Xiao, J.; et al. Reduction of air pollutants and associated mortality during and after the COVID-19 lockdown in China: Impacts and implications. Environ. Res. 2021, 200, 111457. [CrossRef]

55. Schwert, G.W. Tests For Unit Roots: A Monte Carlo Investigation. J. Bus. Econ. Stat. 1988, 20, 5-17. [CrossRef]

56. He, L.; Wu, M.; Wang, D.; Zhong, Z. A study of the influence of regional environmental expenditure on air quality in China: The effectiveness of environmental policy. Environ. Sci. Pollut. Res. 2017, 25, 7454-7468. [CrossRef]

57. Chen, S.; Zhang, Y.; Zhang, Y.; Liu, Z. The relationship between industrial restructuring and China's regional haze pollution: A spatial spillover perspective. J. Clean. Prod. 2019, 239, 115808.

58. Zhang, M.; Sun, X.; Wang, W. Study on the effect of environmental regulations and industrial structure on haze pollution in China from the dual perspective of independence and linkage. J. Clean. Prod. 2020, 256, 120748. [CrossRef]

59. Hebei Provincial Department of Finance. Hebei Province Accurately Builds a Key Undertaking Platform System. 2020; (In Chinese). Available online: http://czt.hebei.gov.cn/xwdt/zhxw/202008/t20200817_1285302.html (accessed on 25 November 2021).

60. Pei, T.; Gao, L.; Yang, C.; Xu, C.; Tian, Y.; Song, W. The Impact of FDI on Urban PM2.5 Pollution in China: The Mediating Effect of Industrial Structure Transformation. Int. J. Environ. Res. Public Health 2021, 18, 9107. 
61. Xue, W.; Zhang, J.; Zhong, C.; Li, X.; Wei, J. Spatiotemporal PM2.5 variations and its response to the industrial structure from 2000 to 2018 in the Beijing-Tianjin-Hebei region. J. Clean. Prod. 2021, 279, 123742.

62. Liu, H.; Wang, X.; Pang, J.; He, K. Feasibility and difficulties of China's new airquality standard compliance: PRD case of PM2.5 and ozone from 2010 to 2025. Atmos. Chem. Phys. 2013, 13, 12013-12027.

63. Li, M.; Wang, T.; Xie, M.; Zhuang, B.; Li, S.H.Y.; Chen, P. Impacts of aerosol-radiationfeedback on local air quality during a severe haze episode in Nanjing megacity, eastern China. Tellus Ser. B-Chem. Phys. Meteorol. 2017, 69, 1339548.

64. Arter, C.A.; Buonocore, J.; Chang, C.; Arunachalam, S. Mortality-based damages per ton due to the on-road mobile sector in the Northeastern and Mid-Atlantic U.S. by region, vehicle class and precursor. Environ. Res. Lett. 2021, 16, 065008. [CrossRef]

65. Wu, B.; Liu, C.; Zhang, J.; Du, J.; Shi, K. The multifractal evaluation of PM2.5-O3 coordinated control capability in China. Ecol. Indic. 2021, 129, 107877. [CrossRef]

66. Jephcote, C.; Hansell, A.L.; Adams, K.; Gulliver, J. Changes in air quality during COVID-19 'lockdown' in the United Kingdom. Environ. Pollut. 2021, 272, 116011. [PubMed]

67. Wolff, G.T.; Kahlbaum, D.F.; Heuss, J.M. The vanishing ozone weekday/weekend effect. J. Air Waste Manag. Assoc. 2012, 63, $292-299$. 